J. Dairy Sci. 102:6700-6700

https://doi.org/10.3168/jds.2019-102-7-6700

(c) American Dairy Science Association ${ }^{\circledR}, 2019$.

\title{
Corrigendum to "Randomized prospective trials to study effects of reduced antibiotic usage in abdominal surgery in cows" (J. Dairy Sci. 101:8217-8223)
}

\section{R. Jorritsma, I. M. van Geijlswijk, and M. Nielen}

An error was noted in Table 2 (page 8221). The number needed to treat (NNT) for "Needed antibiotic treatment" was amended to "-." because this variable has no clear interpretation.

The authors regret the error.

Table 2. Descriptive results of cows submitted for exploratory laparotomy with different antibiotic prophylaxis (ELN and ELL)

\begin{tabular}{|c|c|c|c|}
\hline Variable & $\mathrm{ELN}^{1}$ & ELL $^{2}$ & $\mathrm{NNT}^{3}$ \\
\hline Complication, ${ }^{4} \%$ (no.) & $\begin{array}{c}1.9 \\
(52)\end{array}$ & $\begin{array}{c}0 \\
(51)\end{array}$ & 53 \\
\hline Needed antibiotic treatment, ${ }^{5} \%$ (no.) & $\begin{array}{l}1.9 \\
(54)\end{array}$ & $\begin{array}{l}7.1 \\
(56)\end{array}$ & - \\
\hline Wound score $\geq 2, \%$ (no.) & $\begin{array}{l}12.5 \\
(48)\end{array}$ & $\begin{array}{c}4 \\
(50)\end{array}$ & 12 \\
\hline Median percentage infected sutures, $\%$ (minimum-maximum) & $\begin{array}{l}0 \\
(0-100)\end{array}$ & $\begin{array}{l}0 \\
(0-31)\end{array}$ & - \\
\hline
\end{tabular}

${ }^{1}$ No antibiotic prophylaxis.

${ }^{2}$ Antibiotic prophylaxis with a single 5-g i.v. injection of ampicillin-sodium.

${ }^{3}$ Number needed to treat (NNT) was calculated as $1 /$ (risk difference).

${ }^{4}$ The need to treat the cow with antibiotics for peritonitis or sepsis within $10 \mathrm{~d}$ after surgery.

${ }^{5}$ All antibiotic use within $10 \mathrm{~d}$ postsurgery for any indication.

\section{REFERENCES}

Jorritsma, R., I. M. van Geijlswijk, and M. Nielen. 2018. Randomized prospective trials to study effects of reduced antibiotic usage in abdominal surgery in cows. J. Dairy Sci. 101(9):8217-8223. https://doi.org/10.3168/jds.2017-14158. 